\title{
Sobre a imaterialidade do objeto de estudo do Jornalismo Gislene Silva
}

\section{Resumo}

A busca por uma teoria que não importe recursos conceituais e teóricos de outros campos e se concentre na formulação e estudo de seu próprio objeto se coloca como desafio persistente na pesquisa do Jornalismo. Ao tentar demarcar seu objeto, esta subárea reproduz atitudes epistemológicas muito vistas no campo maior da Comunicação, num movimento pendular entre a opção pela eleição da centralidade da técnica, meio e formação profissional - a investigação do Jornalismo para resolver problemas desta prática social - ou pela crítica e abordagem transdisciplinar - para formular problemas e compreender este fenômeno comunicativo. Tais opções, quando excludentes, são apontadas como responsáveis pela fragilidade teórica das pesquisas em Jornalismo. Este artigo discute impasses em se localizar o objeto de estudo do Jornalismo exclusivamente nas especificidades de seus produtos materiais, no caso o jornal, a revista, o telejornal, o radiojornal e os sítios de notícia. As incontáveis manifestações empíricas do objeto não devem ser tomadas particularmente pelo próprio objeto, este sempre construído teoricamente e maior do que suas expressões materiais. Confundimo-nos quando falamos em objetos do Jornalismo, no plural. 0 objeto de estudo do Jornalismo deve ser um e para reconhecêlo em suas múltiplas manifestações empíricas necessitamos aprimorar aparatos metodológicos e conceituais, a começar pelo próprio conceito de objeto. Palavras-chave

Jornalismo. Epistemologia. Teoria. Objeto.

\section{Gislene Silva I gislenedasilva@gmail.com}

Professora do Mestrado em Jornalismo da Universidade Federal de Santa Catarina (UFSC).

Apresentado no VIII Lusocom - II Colóquio Portugal-Brasil, em Lisboa Universidade Lusófona, abril de 2009

\section{Introdução}

A busca por uma teoria que não importe recursos conceituais e teóricos de outros campos e se concentre na formulação e estudo de seu próprio objeto se coloca como desafio persistente na pesquisa em Jornalismo. Ao tentar demarcar seu objeto, esta subárea reproduz atitudes epistemológicas muito vistas no campo maior da Comunicação, num movimento pendular entre a primazia dos meios tecnológicos de informação, e seus múltiplos desdobramentos, ou a leitura alargada do fenômeno comunicativo na vida do ser humano. Muito mais do que na Comunicação em geral, porém, a pesquisa em Jornalismo parece confortável com a condição midiática. Não se discute se pensar a imprensa como mídia seria fechar-se em um midiacentrismo. 0 ponto de partida já é a mídia noticiosa, compreendida dentro dos marcos do jornalismo moderno, constituído no século XIX e assim configurado até os dias atuais. É um negócio que se sustenta em dispositivos tecnológicos em evolução, linguagens particulares, públicos diversos e requisitos técnicos, estéticos e éticos, sempre sujeitos às conformações históricas da 
sociedade industrial e urbana, de preferência democrática e, agora, globalizada. Há até, quando se recorre a relatos historiográficos sobre o surgimento do jornal, indicações de que se fazia jornalismo na virada do século XVI para o XVII, época em que se iniciaram as primeiras publicações aperiódicas na Alemanha e na Inglaterra dedicadas a comunicar os eventos mais recentes para a comunidade. Em recuo mais atrás, considera-se que a notícia já existia antes mesmo da impressão, por conta do apreço pelas novidades que acompanha a convivência humana. 0 historiador Mitchel Stephens (apud FRANCISCATO, 2005, p. 30), sugere, inclusive, três formas ou fases na transmissão de notícias: as transmitidas oralmente (spoken news), que seriam a pré-história do jornalismo; as manuscritas em suportes diversos (written news), como as folhas escritas na Roma Antiga, e as impressas mecanicamente (printed news), com 0 nascimento do sistema de impressão e do suporte jornal, específico para veiculação de conteúdos variados da atualidade. Mas foi nos séculos XVII e XVIII que a imprensa ganhou periodicidade uma de suas principais marcas - e no XIX, então, o jornalismo se configurou como uma instituição social, diferente das demais na organização social e tal como podemos observar no século XXI, só que agora marcadamente pela incorporação das novas tecnologias de informação, em especial as digitais. É essa configuração de jornalismo que tem sido tomada hegemonicamente como fenômeno jornalístico a ser pesquisado.
A ancoragem da pesquisa nos produtos e processos da mídia noticiosa mantém à distância as indagações epistemológicas que poderiam propiciar não só o aprimoramento da Teoria do Jornalismo e de seu objeto de estudo como também melhores orientações teóricas às pesquisas parciais, quer empíricas ou não. $\mathrm{Ou}$ seja, dispensadas da angústia frente à força da mediação tecnológica e, como disse anteriormente, tranquilas em relação à condição midiática do fenômeno, as pesquisas do campo do Jornalismo sempre atentaram para as mudanças técnicas da imprensa escrita e para a intervenção tecnológica do radiojornalismo e do telejornalismo, e, no momento, têm demonstrado muito fôlego para investigar o webjornalismo e a imprensa multimídia - a última geração tecnológica dos aparatos da informação jornalística. No entanto, investe-se pouco na compreensão das especificidades do objeto de estudo do campo jornalístico. Devido à materialidade das manifestações empíricas do Jornalismo, tomam o objeto de estudo como algo dado, e não como uma construção conceitual. Quase sempre se faz a opção pela eleição da centralidade da técnica, meio e formação profissional - a investigação do Jornalismo para resolver problemas da prática social. E, quando se opta por uma abordagem crítica e teórica - para formular problemas e compreender este fenômeno comunicativo -, recorre-se geralmente a referenciais de outras disciplinas, e o objeto de estudo do Jornalismo, já difuso, continua não apreendido. 


\section{$2 \mathrm{~A}$ busca pelo núcleo objetivável da Comunicação}

Impasses semelhantes são observados nos estudos epistemológicos da Comunicação.

Ali o debate se acirra entre tomar como objeto de estudo deste campo os processos comunicacionais coletivos mediados tecnologicamente - em outras palavras, a mídia - ou alargar o campo tomando 0 ato comunicativo em si mesmo, seja nos diálogos diretos entre as pessoas, na comunicação em pequenos grupos, nas conversações e interações sociais, nas visualidades urbanas e, claro, também na (in) comunicação midiática. Para Martino (2007b, p. 35-36), a área que se convencionou chamar de Comunicação, Comunicação Social, Ciência da Comunicação ou Media Studies, entre outros nomes, representa apenas uma das possibilidades de abordagem dos fenômenos de comunicação, aquela em torno dos meios tecnológicos de informação e da cultura de massa, não tendo de responder, portanto, a todos os processos comunicativos, a qualquer comunicação humana. As particularidades do fenômeno comunicacional stricto sensu seriam historicamente marcadas: mercantilização da informação, intervenção da técnica, transformação da cultura e relevância central na organização da sociedade complexa. Isto é, o fenômeno comunicacional que interessa para a pesquisa da área não seria todo e qualquer ato relacional. Em entendimento oposto, Lucrécia Ferrara (2003, p. 61-63) argumenta que a explosão de códigos e linguagens na metade do XX faz com que até hoje a comunicação seja confundida com as características dos meios e canais e, com isso, os temas estudados ficam restritos às descrições das potencialidades desses meios informacionais. Sugere a autora que se ouse interrogar não sobre códigos, tecnológicos ou não, mas sobre as relações comunicativas, nutridas inclusive pelas características processuais da mídia. Também a partir de uma abordagem expandida, Marcondes Filho propõe uma Nova Teoria da Comunicação, definindo 0 fenômeno da comunicação como uma "relação entre pessoas, um certo tipo de ocorrência em que se cria uma situação favorável à recepção do novo" (MARCONDES FILHO, 2008: 8). Ela pode ocorrer no encontro entre duas pessoas, num grupo, entre a pessoa e um objeto cultural, na população que lê jornal ou vê telenovela. Por isso, para tomar a Comunicação como objeto de estudo, a pesquisa deveria considerar que a comunicação é relação, acontecimento irrepetível, do campo dos sentidos, do afeto, que se dá no durante e não a posteriori, que só existe como ciênciajunto com o objeto, e cujo método é versátil e mutante, sem aspiração à objetividade, mais ao estilo da reportagem jornalística e da literatura; 0 objeto de estudo da Comunicação estaria no campo intermediário entre ficção e ciência (MARCONDES FILHO, 2008, p. 151-153).

A questão parece sempre ser o desafio de enfrentar uma necessidade de unificação do que se mostra fragmentado, bipartido em de massa e interpessoal, mediado tecnologicamente e não 
mediado pela tecnologia, comunicação social e comunicação humana. Ou ainda em midiatização (processos técnicos de controle e produção de bens simbólicos) e mediações (processos de produção de sentido) (MALDONADO, 2003. p. 212). Muniz Sodré (2002), ao discutir a relação communicatio e epistème, tem como ponto de chegada a proposição de uma nova posição interpretativa do processo comunicacional, uma 'antropológica' base reflexiva, pós-epistemológica e pós-ontológica. Começa criticando os limites impostos pela fixação nas práticas de mídia:

Efetivamente, se olharmos para o campo comunicacional apenas como um mero reflexo das práticas de mídia, sempre orientadas para uma antecipação acelerada do futuro, a cognição daí decorrente não parecerá dispor de qualquer objeto próprio. Por outro lado, é difícil pensar no conceito de 'um' objeto para uma disciplina social atravessada pela profunda fragmentação, tanto dos fenômenos que procura conhecer quanto de seu próprio campo teórico (SODRÉ, 2002, p. 222).

Apesar disso, como ele mesmo diz, é possível sustentar que, se não com 'um' objeto claramente discernível, a Comunicação detém hoje um nó ou núcleo objetivável. Dado o caráter transdisciplinar dos estudos de Comunicação, é compreensível, segundo Sodré, que pairem dúvidas e sombras sobre esse núcleo objetivo. Mas considerando a possibilidade do fio condutor de sentido, 0 autor sugere como núcleo objetivável a vinculação entre o eu e o outro, a apreensão do ser-em-comum (individual ou coletivo), seja sob a forma da luta social por hegemonia política e econômica, seja sob a forma do empenho ético de reequilibração das tensões comunitárias. Noutro texto, ao colocar momentaneamente em suspenso a ideia de que vivemos num tempo de "energias pós-ontológicas" e se dispor a pensar sobre a episteme comunicacional, ainda na ordem do ontológico, Sodré (2007, p. 22) explicita essas formas em que o objeto conceitual se desdobra. A luta social deve ser entendida no nível relacional ou da veiculação e as tensões comunitárias no nível da vinculação. 0 da veiculação/relacional trata das antropotécnicas ou práticas de natureza empresarial (privada ou estatatal) voltadas para o contato entre sujeitos sociais por meio de tecnologias informacionais como imprensa escrita, rádio, televisão, publicidade etc, sendo societal a natureza dos dispositivos da mídia. Quer dizer, a retórica aqui seria eletronicamente materializada e ampliada pelos dispositivos tecnológicos de comunicação. Trata-se da midiatização. A vinculação, por sua vez, define-se como condição originária do ser, lugar social da interação intersubjetiva, "práticas estratégicas de promoção ou manutenção do vínculo social, empreendidas por ações comunitaristas ou coletivas", pautando-se por modos diversos de reciprocidade comunicacional (afetiva e dialógica) entre os indivíduos, e, portanto, de natureza sociável (Sodré, 2002, p. 234).

Haveria ainda um terceiro nível, o da cognição, ou crítico-cognitivo, justamente 0 das práticas teóricas que se dedicam a observar e sistematizar as estratégias de veiculação/relacional e as 
de vinculação a partir do núcleo objetivável.

0 que é este terceiro espectro de práticas da

Comunicação se não o esforço em conjugar

teoricamente os dois anteriores, que insistem em

manter seu afastamento no movimento pendular?

Se não a necessidade de perseguir a unidade da

Comunicação em seus dois clássicos processos?

- o primeiro, o processo comunicativo (aquele

que põe em comum as diferenças por meio do

discurso, com ou sem 0 auxílio da retórica); 0

segundo, o processo comunicacional (o que

interpreta os fenômenos constituídos pela

ampliação tecnológica da retórica, isto é, pela

mídia, na sociedade contemporânea), ainda nas

definições de Sodré (2007, p. 18).

0 nível crítico-cognitivo, assim posto, parece ser também uma proposta de Nova Teoria da Comunicação, capaz de enfrentar de modo semelhante 0 caráter dispersivo do objeto da Comunicação, diante principalmente de suas incontáveis manifestações empíricas. De acordo com Sodré (2007, p. 20), "a atração empírica dos fenômenos comunicativos sob a égide da tecnologia avançada dá margem à suspeita de que uma 'ciência' da comunicação se faz impossível pelo estado disperso e caótico do provável objeto", e que por isso tem-se preferido falar atualmente em 'campo' comunicacional, sem maior unidade epistemológica.

No entanto, quando aceitamos definir a física como estudo das leis que regem o funcionamento do mundo material, estamos perfeitamente cientes de que 0 universo estudado comporta diversidade e caos. É o que se divisa no caso da comunicação: a multiplicidade dos fenômenos comunicativos converge reflexivamente para uma identificação teórica da comunicação como 'vínculo' intersubjetivo, seja no nível das operações discursivas para a produção de sentido, seja no nível das formações sociais de controle e gestão do vínculo pelo discurso, como as desenvolvidas no âmbito da midiatização (SODRÉ, 2007, p. 20).

Como o núcleo objetivável implicaria

obrigatoriamente essas duas instâncias de comunicabilidade, seria sempre redutor privilegiar no problema a relação tecnológica, a condição midiática - muito embora essa escolha seja mais confortável, e com mais eficiência aplaque a insegurança epistemológica do campo da Comunicação. Logo, por tudo isso, a vontade de teorias mediadoras. Para Martino (2007b, p. 23) seria equivocado supor que "a solução deva ser buscada na forma de uma improvável 'teoria geral', conciliadora - verdadeiro lugar geométrico ou centro gravitacional desse emaranhado teórico". Tudo se passaria "como se a chave do problema da fundamentação de uma área de conhecimento fosse qualquer tipo de consenso, ou, na falta dele, a simples afirmação de sua indefinição". A publicação de teorias gerais, porém, tem surgido em intervalos regulares, diz Miège, como uma queda de braços teórica que menospreza o que foi dito anteriormente, para "afirmar com mais convicção a radical novidade de sua proposta" (MIÈGE, 2000, p.102). Apesar da dura crítica aos limites das teorias gerais, Miège também incorre na mesma vontade de unidade, 
de juntar duas instâncias para compor um todo que dê conta de entender a complexidade dos fenômenos de comunicação. A essa unidade dá o nome de pensamento comunicacional: uma articulação de contribuições teóricas (conhecimento acadêmico) e contribuições da atividade profissional e social (conhecimento midiático), isto é, um pensamento que provém concomitantemente das representações ligadas às práticas dos profissionais da informação como de proposições teóricas, que supera, quase sempre, camadas disciplinares. Ele resulta da reflexão especulativa e da produção científica,

[...] é, ao mesmo tempo, organizador de práticas científicas, reflexivas ou profissionais; resposta a necessidades que surgem dos Estados e das grandes organizações, assim como inspirador de mudanças que intervêm em tais organizações; por fim, está na origem ou no acompanhamento de mudanças nas práticas culturais ou nas modalidades de difusão ou aquisição de conhecimentos (MIĖGE, 2000 p. 21).

Também Marques de Melo, quando se dedica a inventariar estudos sobre atos e processos massmidiáticos, leva em conta duas perspectivas assemelhadas às de Miège: a vertente de natureza midiológica, que sistematiza teorias e metodologias relativas a fenômenos de comunicação de massa e suas inter-relações com os da comunicação interpessoal ou grupal, e "recusa o protagonismo dos meios de comunicação enquanto difusores de mensagens ou significados, reivindicando a primazia das mediações entre técnica e cultura, entre ideologias e as tecnologias midiáticas"; e a vertente de natureza midiática, que acumula "evidências sobre processos de produção, difusão, recepção e retroalimentação de mensagens mediadas por tecnologias de largo alcance ou de porte industrial" (MEL0, 2003, p. 113-114). É um entendimento que demonstra igualmente a inclusão no pensamento comunicacional de demandas sociais e profissionais, numa outra intenção de unificação teórica. 0 problema é que na pesquisa em Jornalismo muitas vezes considera-se como objeto de estudo "a natureza da prática em jornalismo" e como ‘função' da pesquisa apenas "contribuir para 0 aperfeiçoamento do jornalismo enquanto prática social" (MACHAD0, 2004).

\section{Para além da matéria jornalística}

As reflexões sobre o pensamento comunicacional podem ajudar a entender melhor o fenômeno jornalístico e o objeto de estudo do que temos chamado de Teoria do Jornalismo ou Campo Jornalístico, ultrapassando os limites das abordagens centradas na prática profissional e nos produtos jornalísticos que circulam no mercado. Miège lembra que o pensamento comunicacional foi construído inicialmente como um pensamento setorial, específico de alguns campos da atividade social e praticamente fora de qualquer relação próxima com os sistemas filosóficos e intelectuais existentes (MIÈGE, 2000, p. 87). Sodré também pontua diferenças:

Diferentemente das disciplinas como sociologia, antropologia, psicologia e História, que emergi- 
ram academicamente a partir do 'continente' filosófico, a Comunicação partiu tanto da Academia quanto do mercado e sempre teve maior peso prático (é um tipo de saber estreitamente ligado à produção de serviços) do que conceitual. Nesta conjuntura, simplesmente inexiste consenso teórico quanto a seu objeto (SODRÉ, 2002, p. 222).

Além disso, enquanto as demandas de conhecimento sociológico, antropológico e psicológico provêm principalmente de organismos ligados direta ou indiretamente ao Estado (órgãos de planejamento, de administração de territórios, de controle de comportamento e atitudes etc), as questões a que busca responder o estudioso dos fenômenos comunicacionais, desde a primeira década do século XX, partem primordialmente de empresas de mídia, organizações privadas; um saber priorizado pelo mercado, portanto. (SODRÉ, 2007, p. 18).

Talvez esteja aí a dificuldade de se pensar o objeto do Jornalismo para além de sua materialidade. Objeto de estudo deve ser colocado como uma construção teórica, concebida e alimentada pelos múltiplos objetos nos quais ele se manifesta empiricamente. Por isso a fragilidade epistemológica e teórica quando se localiza 0 objeto de estudo do Jornalismo exclusivamente nas especificidades de seus produtos materiais, no caso as matérias jornalísticas ou processos produtivos do jornal, revista, telejornal, radiojornal e sítios de notícia. As incontáveis manifestações empíricas do objeto não devem ser tomadas particularmente como o próprio objeto de estudo, este sempre construído teoricamente e maior do que suas expressões materiais.

Confundimo-nos quando falamos em objetos do Jornalismo, no plural. Inumeráveis são os modos como o fenômeno jornalístico se mostra, todos eles disponíveis para serem identificados e escolhidos como objetos de pesquisa, objetos de análise, tanto quanto são os pesquisadores e suas interrogações. Como a mídia se expressa materialmente - um veículo, um programa de rádio, uma reportagem impressa, um telejornal, uma manchete, um acontecimento, um tema -, costuma-se ver definido como objeto de estudo o jornal tal, as matérias de uma revista específica, um assunto tratado pela cobertura jornalística. Martino, falando da grande área Comunicação, atenta:

[...] em relação ao fenômeno, é preciso ter em conta que não se trata de um objeto empírico, mas construído através de uma elaboração teórica. Isso significa dizer que tal objeto somente pode aparecer a partir do arcabouço teórico ou da tradição de pensamento de uma disciplina. [...] uma teoria somente pode ser considerada teoria da comunicação se respeitar 0 preceito da centralidade do fenômeno comunicacional. Isto significa dizer que a realidade humana deve ser explicada (entendida, descrita) tomando-se a comunicação como fator privilegiado. Assim, se 0 economista explica através da centralidade dos fenômenos econômicos (mercado); e 0 sociólogo 0 faz através dos fenômenos sociais (evolução, estrutura, organização social) [...] 0 comunicólogo deve explicar a realidade a partir dos fenômenos comunicacionais. [...] Daí seu nome comunicacional, pois toma a comunicação não necessariamente como causa, mas como fator central para a compreensão desses fenômenos. É este engajamento - hipotético, perspectivado - que caracteriza uma teoria 
como pertinente a uma disciplina (MARTINO, 2007b, p. 27- 28).

Haveria um centro de gravidade, um núcleo, expressado na ideia de objeto de estudo, complementa Martino (2007b, p. 127). Termo não muito diferente do núcleo objetivável de que falava Sodré, à parte a concepção de cada um; e que eu chamaria de núcleo epistêmico. Se assumirmos 0 ato de dar e receber notícia como fenômeno comunicacional - um entre os muitos estudados pela Comunicação - poderemos entender e explicitar a especificidade do objeto de estudo concernente ao subcampo do Jornalismo, confirmando o jornalismo como uma prática eminentemente comunicacional, no que tem de midiático, perspectiva relacional, interação social, lugar de poder, necessidade social, circulação de discursos sociais, narrativa mítica, troca simbólica e cultural, dimensão imaginária etc. Se é problemático o menosprezo de estudiosos da comunicação pelas questões da informação e, na sequência, também pela proximidade com o demandante universo profissional, como aponta Miège (2000, p. 106), igualmente é questionável o desejo de estudiosos da informação jornalística em pretender um campo autônomo, afastado da Comunicação. 0 problema nessa pretensão é ver na prática profissional o certificado científico do campo. Conforme discutimos em outro texto (SILVA; PONTES, 2008), há na pesquisa em Jornalismo um empirismo descritivo que ganha maior visibilidade em alguns tipos de investigação, naquelas que podemos localizar no universo das Teorias da Notícia, circunscritas às técnicas, processos e produtos da rotina profissional. Os entraves se dão nos modos como elas são feitas. A Teoria do Jornalismo tem sido colocada, na maioria dos casos, como um exercício secundário. Ao considerar como sinônimos Teoria do Jornalismo e Teoria da Notícia (como faz SOUSA 2002), toma-se, metonimicamente, parte do objeto do Jornalismo como todo o objeto da Teoria do Jornalismo. Desse modo, dribla-se a insegurança teórica fixando-se na empiria do mundo prático da profissão, na expectativa de que a materialidade dos produtos e processos jornalísticos responda naturalmente pela teoria. Esse caminho decorre, quase sempre, em um insistente empirismo descritivo e em espontaneísmos. Mas, como reforça Martino,

Falar de objeto de estudo é na verdade falar de um saber teórico que fornece uma representação do mundo, ou de um mundo que aparece por meio desse saber. [...] não se trata de coisas, de objetos naturais, mas de objetos de estudo, que só aparecem por meio de uma teoria, de uma apreensão não naturalizada, mas produzida por um modelo teórico. 0 objeto de estudo é, portanto, uma construção teórica ou 0 objeto de uma teoria. Ele não é o fenômeno que se dá na percepção ordinária, mas justamente aquilo que no fenômeno é recortado por uma teoria (MARTINO, 2003, p. 86).

[...] objeto significa aquilo que se dá a ver ou conhecer para um sujeito [...] pois a coisa nela mesma não é um objeto, as coisas passam a ser objetos em função de um ato de conhecimento por parte do sujeito; por outro lado não 
podemos falar de sujeito em si, pois todo sujeito é conhecido e se deixa conhecer por sua relação com o objeto (MARTINO, 2003, p. 85).

Por isso o cuidado em fazer, como Martino, a distinção entre objeto de estudo (geral) e objeto de pesquisa (específico), este último a matéria intelectual que o pesquisador manipula e que só aparece nas elaborações teóricas pelas quais os fenômenos se apresentam à investigação científica, opondo-se, assim, ao objeto empírico. Já 0 objeto de estudo (de uma disciplina) é 0 ponto de vista geral, responsável pelo recorte e abordagem por meio da qual o fenômeno se apresenta ao trabalho de teorização, o princípio da diferença e da unidade do campo. Outros estudiosos da epistemologia da Comunicação também insistem nesse esclarecimento e apontam o objeto problematizado, ou seja, a não circunscrição do objeto de estudo ao universo recortado de objetos empíricos, mas à delimitação de um objeto de conhecimento (MAIA e FRANÇA, 2003; LOPES; FUENTES NAVARR0, 2005). Se essa escolha é mais um olhar epistemológico do que o fechamento em uma disciplina, como recomenda Luís Carlos Lopes, devemos também considerar, como faz 0 autor, que os objetos de cultura são representacionais. "Se forem artefatos físicos, só se incorporam animando-se como objetos culturais. Se forem apenas representações mentais, precisam ser socialmente aceitos" (2003, p. 170). Para Martino (2003, p. 88), o objeto de estudo é o elemento de inteligibilidade tanto da diversidade teórica como também da multiplicidade material e imaterial pelas quais o jornalismo se dá a conhecer. Só não penso, como o autor, que teremos tantos objetos de estudo quantas forem as abordagens diferentes, não consensuais. Se for para falar em objeto de estudo de um campo epistêmico específico, teremos de elaborar acordos. Não me refiro às teorias parciais, às hipóteses diversas, que quanto mais dissonantes mais podem nos aproximar do fenômeno da comunicação jornalística. Mas sim a uma inteligibilidade.

0 objeto de estudo do Jornalismo, então, deve ser a singularidade da perspectiva que busca a explicação ou a compreensão de um fenômeno social específico que se manifesta de incontáveis modos, desde os mais visíveis materialmente, atraentes à observação empírica, até situações de comunicação jornalística impalpáveis, incorpóreas. Tais manifestações jornalísticas se transformam historicamente, como ação política, estratégia de negócio, discurso e narrativa, dispositivo tecnológico, mediação de sensibilidade, experiência estética e cultural, circunscritas todas na relação entre sujeitos sociais. A meu ver, a fragmentação do campo comunicacional ou a dificuldade em se conceber um centro de gravidade epistemológico não se deve à sua herança de habilidades práticas, muito embora a visão que temos hoje de produção teórica em Jornalismo esteja mesmo excessivamente contaminada pela ideia de ciência aplicada. Sendo assim, a inserção das teorias jornalísticas no debate epistemológico da 
Comunicação tanto pode reduzir o pouco caso que se faz do trabalho da imprensa como fenômeno comunicacional com densidade para reflexão teórica, como "recolocar o problema teórico em suas verdadeiras bases, como problema de articulação entre teoria e prática, procurando situar esta última [prática jornalística] na arquitetura comunicacional das sociedades complexas e não somente no imediatismo da ação profissional", como observa Martino (2007a, p. 108).

Possivelmente, o trabalho da Teoria do Jornalismo começa pela problematização do conceito de notícia. Conforme sugerimos (SILVA; PONTES, 2008), uma concepção de notícia está além das possibilidades que uma abordagem descritiva pode lhe dar. A elevação da notícia para o status de categoria-chave possibilitará enxergá-la não só nas hard news, mas também nas soft news; não apenas nas matérias sobre política, mas nas de cultura e arte; não somente no lead e sublead, mas também nas matérias do jornalismo sensacionalista, gonzo ou popular, no novo jornalismo e no jornalismo literário. São trilhas teóricas para formular e responder a questões que extrapolem as atividades das redações ou os textos jornalísticos; que complexifiquem a necessidade social de notícia, ou seja, as razões por que o público quer se informar. Portanto, o objeto de estudo do campo científico do Jornalismo teria como núcleo objetivável a centralidade da notícia como prática social, política e cultural. E para escapar do espontaneísmo oferecido pelas evidências da prática, da "ilusão de transparência" que leva ao "senso comum erudito", e para fazer a ruptura epistemológica, como recomendam Bourdieu, Chamboredon e Passeron (2004), seria necessário adotar como procedimento metodológico a arte da boa distância, sugerida por Philippe Descola: de muito perto perdemos toda a capacidade de objetivar o outro por excesso de identificação; de muito longe perdemos os meios de compreender o que nos identifica (1999, p. 112). Ou pegar emprestado o conselho que Marc Augé (1994) dá ao antropólogo: deixar-se condenar ao estrabismo metodológico: não perder de vista nem o lugar imediato de sua observação nem as fronteiras pertinentes de seus limites exteriores. Com isso, quero dizer que a matéria do Jornalismo é maior e mais complexa que sua própria materialidade. Encontra-se ela também na sua imaterialidade, que não é menos real.

\section{Referências bibliográficas}

AUGÉ, Marc Augé. Não-lugares: introdução a uma antropologia da supermodernidade. Campinas: Papirus, 2004.

BOURDIEU, Pierre; CHAMBOREDON, Jean-Claude; PASSERON, Jean-Claude. Ofício de sociólogo: metodologia da pesquisa na sociologia. Petrópolis: Vozes, 2004.

DESCOLA, Philippe. La nature: une concept en sursis?. In: PASSIS-PASTERNAK, Guitta (org.) La science: dieu ou diable? Paris: Odile Jacob, 1999.

FERRARA, Lucrécia D'Alessio. Epistemologia da Comunicação: além do sujeito e aquém do objeto. In: LOPES, Maria Immacolata Vassallo de (org). 
Epistemologia da Comunicação. São Paulo: Loyola, 2003.

FRANCISCATO, Carlos. E. A fabricação do presente: como o jornalismo reformulou a experiência do tempo nas sociedades ocidentais. São Cristóvão: UFS; Aracaju: Fundação Oviêdo Teixeira, 2005.

Desafios para pensar a geração de conhecimento no campo do jornalismo. In: XXXI CONGRESSO BRASILEIRO DE CIÊNCIAS DA COMUNICAÇÃo, 31., 2008, Natal. Anais... Natal: Intercom, 2008. CD-ROM.

FUENTES NAVARR0, Raúl (2003). La producción social de sentido sobre la producción social de sentido: hacia la construcción de um marco epistemológico para los estúdios de la comunicación. In: LOPES, Maria Immacolata Vassalo de (org). Epistemologia da comunicação. São Paulo: Loyola, 2003.

LOPES, Luís Carlos. Hermenêutica, teorias da representação e da argumentação no campo da Comunicação. In: LOPES, Maria Immacolata Vassalo de (org). Epistemologia da comunicação. São Paulo: Loyola, 2003.

LOPES, M. Immacolata Vassalo de (2003). Sobre o estatuto disciplinar do campo da Comunicação. In: LOPES, Maria Immacolata Vassalo de (org). Epistemologia da comunicação. São Paulo: Loyola, 2003.

LOPES, Maria Immacolata Vassalo de; FUENTES NAVARRO, Raúl (comps). Comunicación: campo y objeto de estúdio - perspectivas reflexivas latinoameriacanas. Guadalajara, México: UTESO; Universidade de Guadalajara; Aguascalientes, México: Universidad Autónoma de Aguascalientes; Colima, México: Universidad de Colima, 2005.

MACHAD0, Elias. Dos estudos sobre jornalismo às teorias do jornalismo (três pressupostos para a consolidação do jornalismo como campo de conhecimento). E-compós - Revista eletrônica da Associação Nacional dos Programas de Pós-
Graduação em Comunicação, Brasília. ed.1, p. 2-15, dez 2004. Disponível em: < www.compos.org.br/ecompos $>$. Acesso em: 10 fev. 2008.

MAIA, Rousiley C. M.; FRANÇA, Vera V. A comunidade e a conformação de uma abordagem comunicacional dos fenômenos. In: LOPES, Maria Immacolata Vassallo de (org). Epistemologia da Comunicação. São Paulo: Loyola, 2003.

MALDONADO, A. Efendy. Explorações sobre a problemática epistemológica no campo das ciências da Comunicação. In: LOPES, Maria Immacolata Vassallo de (org). Epistemologia da Comunicação. São Paulo: Loyola, 2003.

\section{MARCONDES FILHO, Ciro. Para entender a} comunicação: contatos antecipados com a Nova Teoria. São Paulo: Paulus, 2008.

MARTINO, Luiz Claudio. As epistemologias contemporâneas e 0 lugar da Comunicação. In: LOPES, Maria Immacolata Vassalo de (org). Epistemologia da comunicação. São Paulo: Loyola, 2003. . Os cursos de teoria da comunicação à luz do jornalismo: obstáculos e impropriedades das posições tecnicista e intelectualista. In: Ferreira, Giovandro M; Martino, Luís Carlos (orgs). Teorias da Comunicação: epistemologia, ensino, discurso e recepção. Salvador: EDUFBA, 2007a. ; BERGER, Charles; CRAIG, Robert T. Teorias da comunicação: muitas ou poucas? Cotia: Ateliê Editorial, 2007b.

MELO, José Marques de. Midiologia brasileira: 0 resgate das fontes paradigmáticas. In: LOPES, Maria Immacolata Vassallo de (org). Epistemologia da Comunicação. São Paulo: Loyola, 2003.

MIÉGE, Bernard. 0 pensamento comunicacional. Petrópolis: Vozes, 2000.

SILVA, Gislene. Problemática metodológica em jornalismo impresso. In: XXXI CONGRESSO BRASILEIRO DE CIÊNCIAS DA COMUNICAÇÃO, 31., 
2008, Natal. Anais... Natal: Intercom, 2008. CD-ROM.

SILVA, Gislene; PONTES, F. (2008). "Teorias da notícia: impasses para uma Teoria do Jornalismo". In: ENCONTRO NACIONAL DE PESQUISADORES EM JORNALISM0, 6., 2008, São Bernardo do Campo. Anais... São Bernardo do Campo: SBPJor, 2008.

SODRÉ, Muniz. Antropológica do espelho: uma teoria da comunicação linear e em rede. Petrópolis: Vozes, 2002.

Sobre a episteme comunicacional. MATRIZes

- Revista do programa de Pós-Graduação em Ciências da Comunicação, São Paulo, ano I, n.1, p. 15-26, jul.-dez. 2007.

SOUSA, Jorge Pedro. Teorias da notícia e do jornalismo. Chapecó: Argos, 2002. 


\section{On the immateriality of Journalism's object of study}

\section{Abstract}

The search for a theory of journalism that does not import conceptual and theoretical resources from other fields of activity but rather concentrates itself in the formulation and study of its own object represents a continuous challenge for researchers of the field. In trying to mark out its territory this subarea ends up reproducing epistemological attitudes often seen in the bigger field of communication studies, in a pendular movement that veers towards the centrality of technical expertise (journalism investigated as a means to solve specific problems of this social practice) or towards multidisciplinary criticism (which formulates and tries to understand journalism as a communicative phenomenon). These two options, when isolated, are taken to be responsible for the theoretical fragility of research in journalism. This essay analyses the problems of finding journalism's object of study exclusively in the specificities of its material products (magazines, newspapers, radio, television and news sites). The many empirical manifestations of the object cannot be taken to be the object itself, this one always bigger than its material manifestations and always theoretically construed. We incur in error when speaking of journalism and its "objects" in plural form. Journalism's object of study must be one, but in order to recognize its multiple empirical manifestations we must improve conceptual and methodological apparatuses, beginning with the concept of object of study.

\section{Keywords}

Journalism. Epistemology. Theory. Object.

\section{Sobre la imaterialidad del objeto de estudio del Periodismo}

\section{Resumen}

La búsqueda por una teoría que no importe recursos conceptuales y teóricos de otros campos y se concentre en la formulación y estudio de su propio objeto se coloca como desafío persistente en la investigación del Periodismo. Al intentar demarcar su objeto, esta subárea reproduce actitudes epistemológicas muy observadas en el campo más amplio de la Comunicación, en un movimiento pendular entre la opción por la elección de la centralidad de la técnica, medio y formación profesional - la investigación del Periodismo para resolver problemas de esta práctica social - o por la crítica y enfoque transdisciplinar - para formular problemas e comprehender este fenómeno comunicativo. Tales opciones, cuando excluyentes, son apuntadas como responsables por la fragilidad teórica de las investigaciones en Periodismo. Este artículo discute el callejón sin salida en se ubicar el objeto de estudio del Periodismo exclusivamente en las especificidades de sus productos materiales, como el periódico, la revista, los noticiarios en la televisión o en la radio y los sitios de noticia. Las incontables manifestaciones empíricas del objeto no deben ser llevadas en cuenta particularmente por el propio objeto, este siempre construido teóricamente y más amplio que sus expresiones materiales. Nos confundimos cuando hablamos en objetos del Periodismo en el plural. El objeto de estudio del Periodismo debe ser uno y para reconocerlo en sus múltiples manifestaciones empíricas necesitamos perfeccionar aparatos metodológicos y conceptuales, comenzando por el mismo concepto de objeto de estudio.

\section{Palabras clave}

Periodismo. Epistemología. Teoría, Objeto. 


\section{Expediente}

A revista E-Compós é a publicação científica em formato eletrônico da Associação Nacional dos Programas de Pós-Graduação em Comunicação (Compós). Lançada em 2004, tem como principal finalidade difundir a produção acadêmica de pesquisadores da área de Comunicação, inseridos em instituições do Brasil e do exterior.
E-COMPÓS I www.e-compos.org.br I E-ISSN 1808-2599

Revista da Associação Nacional dos Programas de Pós-Graduação em Comunicação. Brasília, v.12, n.2, maio/ago. 2009

A identificação das edições, a partir de 2008 passa a ser volume anual com três números.

\section{CONSELHO EDITORIAL}

\section{Afonso Albuquerque}

Universidade Federal Fluminense, Brasil

Alberto Carlos Augusto Klein

Universidade Estadual de Londrina, Brasi

Alex Fernando Teixeira Primo

Universidade Federal do Rio Grande do Sul, Brasi

\section{Alfredo Vizeu}

Universidade Federal de Pernambuco, Brasil

Ana Carolina Damboriarena Escosteguy

Pontifícia Universidade Católica do Rio Grande do Sul, Bras

Ana Silvia Lopes Davi Médola

Universidade Estadual Paulista, Brasil

André Luiz Martins Lemos

Universidade Federal da Bahia, Brasil

Ângela Freire Prysthon

Universidade Federal de Pernambuco, Brasil

Antônio Fausto Neto

Universidade do Vale do Rio dos Sinos, Brasil

Antonio Carlos Hohlfeldt

Pontifícia Universidade Católica do Rio Grande do Sul, Brasil

Arlindo Ribeiro Machado

Universidade de São Paulo, Brasil

César Geraldo Guimarães

Universidade Federal de Minas Gerais, Brasil

Cristiane Freitas Gutfreind

Pontifícia Universidade Católica do Rio Grande do Sul, Brasil

Denilson Lopes

Universidade Federal do Rio de Janeiro, Brasil

Eduardo Peñuela Cañizal

Universidade Paulista, Brasi

Erick Felinto de Oliveira

Universidade do Estado do Rio de Janeiro, Brasil

Francisco Menezes Martins

Universidade Tuiuti do Paraná, Brasil

Gelson Santana

Universidade Anhembi/Morumbi, Brasi

Hector Ospina

Universidad de Manizales, Colômbia

leda Tucherman

Universidade Federal do Rio de Janeiro, Brasil

Itania Maria Mota Gomes

Universidade Federal da Bahia, Brasil

Janice Caiafa

Universidade Federal do Rio de Janeiro, Brasil

Jeder Silveira Janotti Junior

Universidade Federal da Bahia, Brasil

\section{João Freire Filho}

Universidade Federal do Rio de Janeiro, Brasil

John DH Downing

University of Texas at Austin, Estados Unidos

José Luiz Aidar Prado

Pontifícia Universidade Católica de São Paulo, Brasil

José Luiz Warren Jardim Gomes Braga

Universidade do Vale do Rio dos Sinos, Brasil

Juremir Machado da Silva

Pontifícia Universidade Católica do Rio Grande do Sul, Brasil

Lorraine Leu

University of Bristol, Grã-Bretanha

Luiz Claudio Martino

Universidade de Brasília, Brasil

Maria Immacolata Vassallo de Lopes

Universidade de São Paulo, Brasil

Maria Lucia Santaella

Pontifícia Universidade Católica de São Paulo, Brasil

Mauro Pereira Porto

Tulane University, Estados Unidos

Muniz Sodre de Araujo Cabral

Universidade Federal do Rio de Janeiro, Brasil

Nilda Aparecida Jacks

Universidade Federal do Rio Grande do Sul, Brasil

Paulo Roberto Gibaldi Vaz

Universidade Federal do Rio de Janeiro, Brasil

Renato Cordeiro Gomes

Pontifícia Universidade Católica do Rio de Janeiro, Brasil

Ronaldo George Hela

Universidade do Estado do Rio de Janeiro, Brasil

Rosana de Lima Soares

Universidade de São Paulo, Brasil

Rossana Reguillo

Instituto Tecnológico y de Estudios Superiores do Occidente, México

Rousiley Celi Moreira Maia

Universidade Federal de Minas Gerais, Brasil

Sebastião Carlos de Morais Squirra

Universidade Metodista de São Paulo, Brasil

Simone Maria Andrade Pereira de Sá

Universidade Federal Fluminense, Brasil

Suzete Venturelli

Universidade de Brasília, Brasil

Valério Cruz Brittos

Universidade do Vale do Rio dos Sinos, Brasil

Veneza Mayora Ronsini

Universidade Federal de Santa Maria, Brasil

Vera Regina Veiga França

Universidade Federal de Minas Gerais, Brasil
COMISSÃO EDITORIAL

Ana Gruszynski I Universidade Federal do Rio Grande do Sul, Brasil Felipe da Costa Trotta I Universidade Federal de Pernambuco, Brasil Rose Melo Rocha I Escola Superior de Propaganda e Marketing, Brasil

\section{CONSULTORES AD HOC}

Aníbal Francisco Alves Bragança I Universidade Federal Fluminense, Brasil Benjamim Picado I Universidade Federal da Bahia, Brasil

Carlos Eduardo Franciscato I Universidade Federal de Sergipe, Brasi

Christa Liselote Berger I Universidade Vale do Rio dos Sinos, Brasil

Gisela Castro I Escola Superior de Propaganda e Marketing, Brasil

Luciana Pellin Mielniczuk I Universidade Federal de Santa Maria, Brasi

Marcia Benetti I Universidade Federal do Rio Grande do Sul, Brasil

Paulo Cunha Carneiro Filho I Universidade Federal de Pernambuco, Brasil

Raquel Recuero I Universidade Católica de Pelotas, Brasil

REVISÃO DE TEXTO E TRADUÇÃO I Everton Cardoso

EDITORAÇÃO ELETRÔNICA I Raquel Castedo
COMPÓS I www.compos.org.br

Associação Nacional dos Programas de Pós-Graduação em Comunicação

Presidente

Itania Maria Mota Gomes

Universidade Federal da Bahia, Brasil

itania@ufba.br

Vice-presidente

Julio Pinto

Pontifícia Universidade Católica de Minas Gerais, Brasil

juliopinto@pucminas.br

Secretária-Geral

Ana Carolina Escosteguy

Pontifícia Universidade Católica do Rio Grande do Sul, Brasil

carolad@pucrs.br 